\title{
A NOVA FACETA DO DIREITO À INTIMIDADE NO MEIO AMBIENTE DIGITAL:
} A TIPIFICAÇÃO DO REVENGE PORN

\author{
Silvia Altaf da Rocha Lima Cedrola ${ }^{1}$ \\ Daniel Alberico Resende ${ }^{2}$ \\ Luiz Gustavo Gonçalves Ribeiro ${ }^{3}$
}

RESUMO: O presente artigo tem como objetivo mostrar que as transformações e inovações tecnológicas desencadearam uma necessidade de alteração do ordenamento jurídico pátrio, mais especificamente no Direito Penal. Essa necessidade, ligada ao meio ambiente digital, colide, por vezes, com o direito à intimidade, o que justifica o estudo do chamado revengeporn, mormente a partir da análise das Leis Federais $\mathrm{n}^{\circ} 12.737 / 2012$ e $\mathrm{n}^{\circ} 12.965 / 2014$. Como resultado, verificou-se a relevância da criação de políticas criminais com o escopo de salvaguardar mídias de caráter íntimo. Foi utilizado o método jurídico exploratório, a partir de análises em fontes bibliográficas e documentais.

Palavras-chave: direito penal; vingança pornográfica; meio ambiente digital; princípio da intimidade; privacidade.

\section{THE NEW FACET OF THE RIGHT TO INTIMACY IN THE DIGITAL ENVIRONMENT: THE TYPIFICATION OF REVENGE PORN}

\begin{abstract}
This article aims to show that technological changes and innovations have triggered a need to change the national legal system, more specifically in Criminal Law. This need, linked to the digital environment, sometimes collides with the right to intimacy, which justifies the study of the so-called revenge-porn, especially from the analysis of Federal Laws n. 12,737/2012 and n. 12,965/2014. As a result, the relevance of creating criminal policies with the scope of safeguarding media of an intimate nature was verified. The exploratory legal method was used, based on analyzes in bibliographic and documental sources.
\end{abstract}

Keywords: penal law; pornographic revenge; digital environment; principle of intimacy; privacy.

\section{INTRODUÇÃO}

As sociedades atuais passaram por grandes mudanças e avanços, especialmente em razão das Revoluções Industriais. Nessa perspectiva, houve mudanças culturais,

\footnotetext{
${ }^{1}$ Bacharel em Direito pela Universidade Federal de Juiz de Fora, Minas Gerais. Promotora de Justiça do Estado de Minas Gerais. Mestranda em Direito Ambiental e Sustentabilidade pela Dom Helder - Escola de Direito. Email.silviaaltaf@gmail.com. Orcid: http://orcid.org/0000-0002-6862-6427.

${ }^{2}$ Mestrando em Direito Ambiental e Sustentabilidade pela Escola Superior Dom Helder Câmara. Email: daniel.alberico@hotmail.com. Orcid: https://orcid.org/0000-0003-0934-4953

${ }^{3}$ Pós-doutor pela Università Degli Studi di Messina-IT. Doutor e Mestre pela UFMG. Professor do Programa de Pós-Graduação (mestrado e doutorado) em Direito Ambiental e Desenvolvimento Sustentável da Dom HelderEscola de Direito. Email: 1gribeirobh@gmail.com. Orcid: http://orcid.org/0000-0002-0065-1925
} 
organizacionais e, especialmente, diversas descobertas científicas que permitiram maior comodidade aos seres humanos.

Com esse olhar, durante a segunda metade do século XX, e, especialmente, durante o início do século XXI, a utilização da internet e a sua disponibilização em massa permitiu a divulgação de conteúdos com maior intensidade e de forma extremamente veloz. Outrossim, os inventos eletrônicos, como celulares e computadores intensificaram a troca de conteúdo em massa entre várias sociedades, o que acarretou na revolução da informação.

Com essa modernização e evolução tecnológica houve uma necessidade de adequar o Direito às novas realidades implementadas no meio ambiente digital. A revolução da informação trouxe impactos no comércio, na propaganda e na vida pessoal dos indivíduos. Essas repercussões desencadearam muitos ganhos para toda a sociedade, todavia trouxe uma nova forma de ofender e denegrir as pessoas.

Da mesma forma, intensificou-se a preocupação com o meio ambiente, especialmente nas últimas décadas. Destarte, foram desenvolvidas políticas públicas voltadas para a preservação do meio ambiente natural, artificial e do trabalho, sempre se analisando os avanços tecnológicos que impactassem os meios.

O meio ambiente digital, decorrente do meio ambiente artificial criado pelo homem, permite o compartilhamento de informações e das atividades desenvolvidas, que tem como base a sociedade da informação. Dentro desse ambiente virtual, que serve como meio difusor de conhecimento para facilitar a vida das pessoas, há propagação de atos ilícitos cometidos pelos indivíduos.

Quando isso ocorre, há uma degradação, uma violação do meio ambiente ante ao desrespeito à dignidade da pessoa humana. Assim as vítimas de crimes cometidos dentro desse meio ambiente serão protegidas pelo ordenamento jurídico da mesma forma que eram protegidas outrora.

Nesse contexto, o problema a ser enfrentado consiste em analisar se a tipificação da conduta de revenge porn, por si só, é suficiente para reduzir o número de crimes cometidos no meio ambiente digital. Assim, o tema central do presente artigo é o meio ambiente digital e o revenge porn.

A hipótese deste estudo é de que, embora seja uma inovação necessária no meio ambiente digital, a tipificação da conduta de oferecer, trocar, disponibilizar, transmitir, vender ou expor à venda, distribuir, publicar ou divulgar, por qualquer meio - inclusive por meio de 
comunicação de massa ou sistema de informática ou telemática -, fotografia, vídeo ou outro registro audiovisual que contenha cena de estupro ou de estupro de vulnerável ou que faça apologia ou induza a sua prática, ou, sem o consentimento da vítima, cena de sexo, nudez ou pornografia, não é suficiente para reduzir a prática. Sendo assim, são necessárias políticas públicas auxiliares para que se atinja o objetivo.

O trabalho objetiva evidenciar que essa evolução toda desencadeou a publicação de novas legislações. As inovações do ordenamento jurídico estão em ascensão de modo que consiga acompanhar as mudanças sociais ocorridas, garantindo uma segurança e proteção a toda a sociedade.

Justifica-se a presente pesquisa na medida em que o compartilhamento de vídeos e fotos íntimas é uma prática recorrente em relacionamentos que acabam, como forma de humilhar o ex-parceiro. Diante disso, o estudo é essencial para analisar as evoluções e respostas do poder público no combate a divulgação do conteúdo no meio ambiente digital.

O referencial teórico escolhido é a obra "A criminalização do revenge porn: análise do art. 218-C (Código Penal)”, de autoria de Leandro Ayres França, que analisa a evolução legislativa, especialmente do crime de revenge porn. Também serão utilizadas obras como o estudo "Vazamento não consentido de imagens íntimas no Brasil", de autoria de Leandro Ayres França, e "Crimes no Meio Ambiente Digital”, de autoria de Fiorillo e Conte.

A metodologia empregada neste estudo, em relação ao problema, classifica-se como qualitativa. Em relação ao método de abordagem, classifica-se como jurídico exploratório. No que se refere aos objetivos, se caracteriza como descritiva e explicativa. No que tange as técnicas de coleta será utilizada pesquisa documental, tais como leis e acórdãos, bem como pesquisas bibliográficas como livros e artigos científicos.

No decorrer do presente estudo, será feita uma análise histórica da evolução da internet no Brasil e as evoluções legislativas no mesmo contexto. Além disso, será feita uma análise da caracterização do meio ambiente digital, bem como uma análise da legislação brasileira voltada à regulação da internet. Por fim, será analisado o direito fundamental à intimidade na Constituição da República Federativa do Brasil de 1988.

\section{DIREITO X INTERNET NO BRASIL ${ }^{4}$}

\footnotetext{
${ }^{4}$ Rede de computadores através da qual é possível conectar e interligar computadores ao redor do mundo. Lugar onde ocorre a troca virtual de dados e mensagens, une esses computadores particulares, organizações de
} 
Pode-se dizer que, desde os primórdios, a sociedade sempre é atingida por transformações. Como exemplo, a Revolução Burguesa, que trouxe com ela, a positivação dos direitos; a Revolução Industrial, que transferiu o uso das ferramentas pelo uso de máquinas. E, atualmente, em tempos recentes, a Revolução Digital, tecnologias e serviços que modificaram a forma de vida e o cotidiano das pessoas. Contudo, todo avanço traz problemas e dificuldades.

Enquanto a Revolução Industrial baseou-se em recursos finitos, haja vista serem extraídos da natureza e transformados pelo homem, a Digital é organizada em torno da informação. A Sociedade Informática, também chamada de Pós-Industrial ou do Conhecimento ou Tecnizada ou em Rede, possui recurso infindável, pois a informação é infinita e está em constante movimento, diferente da revolução anterior cujos recursos são esgotáveis. Conclui-se que a informação é um ativo de valor econômico que gera riqueza e poder a quem a detém.

No Brasil, o desenvolvimento tecnológico e científico, teve sua base institucional estruturada a partir do final da década de 40. Foi criada a Sociedade Brasileira para o Progresso da Ciência (SBPC), em 1948; posteriormente foram criados o Conselho Nacional de Pesquisa (CNPq) e a Coordenação de Aperfeiçoamento de Pessoal de Nível Superior (Capes). Na sequência, houve a criação da Financiadora de Estudos e Projetos (FINEP), culminando com a criação do Ministério da Ciência e Tecnologia.

Atualmente, "concebe-se o surgimento dos Megadados, um volumoso conjunto de dados oriundos de diferentes fontes do ciberespaço. Outrossim, o termo Big Data (Grandes Dados) passa a ser utilizado para descrever o complexo de códigos armazenados na Internet" (FRADE; RESENDE; SANTOS, 2021, p. 141). Ademais, os autores (2021, p. 142) complementam dizendo que "essas ferramentas possibilitam um campo amplo de oportunidades para o aprimoramento de tecnologias, porém para entender o seu potencial fazse necessário um estudo detalhado da estrutura dos Megadados".

No período entre as décadas de 30 e 60, no Brasil, houve a modernização do sistema econômico-financeiro, denominado o "milagre brasileiro", com a implantação do sistema industrial. Todavia, foi na década de 80 que houve uma verdadeira revolução tecnológica, em 
razão da origem da "Sociedade Informacional", através da internet, radical mudança ocorreu entre os conceitos de informação e sociedade. Essa inovação remodelou a concepção instituída por toda a população, bem como influenciou todas as relações humanas.

O fenômeno das transformações tecnológicas, a globalização e modificações culturais alcança toda a população tanto presente como as futuras gerações. As consequências dessas inovações afetaram diretamente a função do Direito. Pode-se destacar, mais precisamente, o meio ambiente e, como subespécie, o meio ambiente digital.

Diante deste axioma, para Fiorillo e Conte (2016) o Direito necessita se adequar, sob pena de perder o seu verdadeiro papel, qual seja,

\begin{abstract}
disciplinar as relações sociais e impor normas de conduta. Assim, o Binômio Direito e Internet não constitui fenômenos passageiros. Trata-se de uma realidade ainda um pouco explorada, mas que deve ser analisada sob todos os campos da ciência jurídica, a fim de garantir novos direitos fundamentais, bem como a efetivação dos já existentes. (FIORILLO; CONTE, 2016, p.17)
\end{abstract}

Esta tecnologia inaugurou trazendo uma série de interferências, que repercute nas relações sociais de forma pacífica e prazerosa. Por outro lado, possibilitou a prática de condutas deploráveis socialmente. A tecnologia passa a ser utilizada como ferramenta para a exercício de delitos, o verdadeiro problema da internet, cujos relevantes bens que se encontram em risco ainda não foram adequadamente protegidos pelo ordenamento jurídico.

Podemos descrever alguns problemas desencadeados pela internet como a coleta de dados sem autorização do usuário. O envio indiscriminado de $\operatorname{spam}^{5}$ ou até mesmo o uso de cookies $^{6}$. Temos também as fakes new ${ }^{7}$ que podem influenciar eleições federais, alterando toda uma conjuntura política.

A proteção da intimidade e da privacidade são princípios constitucionais elencados na Constituição Federal, direitos fundamentais da dignidade da pessoa humana. São garantias

\footnotetext{
${ }^{5} \mathrm{O}$ termo Spam pode ser um acrónimo derivado da expressão em inglês "Sending and Posting Advertisement in Mass", traduzido em português "Enviar e Postar Publicidade em Massa", ou também Stupid Pointless Annoying Messages que significa mensagem ridícula, sem propósito, e irritante. https://pt.wikipedia.org/wiki/Spam. Acesso em: 21 de jun. 2021.

${ }^{6}$ Os cookies são utilizados pelos sites principalmente para identificar e armazenar informações sobre os visitantes. Eles são pequenos arquivos de texto que ficam gravados no computador do internauta e podem ser recuperados pelo site que 0 enviou durante a navegação. https://www1.folha.uol.com.br/folha/informatica/ult124u6772.shtml. Acesso em: 21 jun. 2021.

${ }^{7}$ As fake news são notícias com informações ou dados inventados para alterar a interpretação e opinião das pessoas sobre determinados assuntos. O termo vem do inglês fake (falso/falsa) e news (notícia/notícias), ou seja, notícias falsas. https://www.wizard.com.br/idiomas/significado-expressao-em-ingles-fake-news/. Acesso em: 21 jun. 2021.
} 
que preservam o ser humano na sua vida particular. "A privacidade deve ser considerada também como o direito de manter o controle sobre suas próprias informações e de determinar a maneira de construir sua própria esfera particular.” (RODOTÀ, 2008, p. 15). Trata-se, portanto, de um direito essencial e de valor supremo para todos os indivíduos que vivem em sociedade.

O Plenário do Supremo Tribunal Federal, em 07/05/2020, decidiu as cinco Ações Diretas de Inconstitucionalidade (ADIN), que questionavam dispositivos da Medida Provisória número 954/2020, ajuizadas por partidos políticos e pela Ordem ou Conselho Federal dos Advogados do Brasil (OAB), que autorizava o compartilhamento de dados pessoais pelas empresas de telefonia com o Instituto Brasileiro de Geografia e Estatística (IBGE). Ocasião em que a relatora dessas Ações, Ministra Rosa Weber, proferiu o seguinte entendimento:

[...]. 2. Na medida em que relacionados à identificação - efetiva ou potencial - de pessoa natural, o tratamento e a manipulação de dados pessoais hão de observar os limites delineados pelo âmbito de proteção das cláusulas constitucionais assecuratórias da liberdade individual (art. $5^{\circ}$, caput), da privacidade e do livre desenvolvimento da personalidade (art. $5^{\circ}$, X e XII), sob pena de lesão a esses direitos. O compartilhamento, com ente público, de dados pessoais custodiados por concessionária de serviço público há de assegurar mecanismos de proteção e segurança desses dados. [...] 6. Ao não apresentar mecanismo técnico ou administrativo apto a proteger, de acessos não autorizados, vazamentos acidentais ou utilização indevida, seja na transmissão, seja no tratamento, o sigilo, a higidez e, quando o caso, o anonimato dos dados pessoais compartilhados, a MP n ${ }^{\circ}$ 954/2020 descumpre as exigências que exsurgem do texto constitucional no tocante à efetiva proteção dos direitos fundamentais dos brasileiros. [...] (BRASIL, 2020)

Denota-se, portanto, que foi reconhecida a existência do direito fundamental à proteção de dados pessoais na ordem constitucional brasileira, garantindo que o uso de qualquer dado que identifique o indivíduo deva ser protegido constitucionalmente. É perceptível que esse direito deriva do direito fundamental à dignidade humana e da proteção à intimidade (artigo $5^{\circ}$, inciso X da CF /88)."

Sendo assim, é imprescindível que se observe e respeite os direitos fundamentais no meio ambiente digital. Diante disso, no próximo capítulo será analisado e conceituado o meio ambiente digital para melhor entendimento sobre o tema.

\section{MEIO AMBIENTE DIGITAL}


O meio ambiente, como direito de terceira dimensão, positivado na Constituição de 1988, no artigo 225, abarca:

\begin{abstract}
Além do meio ambiente natural (constituído pela atmosfera, elementos da biosfera, águas, mar territorial, solo, subsolo, recursos minerais, fauna e flora), o meio ambiente artificial (espaço urbano construído pelo homem), o meio ambiente cultural (delimitado pelo artigo 216 da CF), o meio ambiente do trabalho (local de desenvolvimento das atividades laborais), o patrimônio genético e, também, o meio ambiente digital", objeto do nosso estudo. (FIORILLO,2016, p. 13)
\end{abstract}

O meio ambiente foi alçado, quando da Constituição de 1988, como direito de todos, das presentes e futuras gerações, pertence a toda a coletividade, considerado um direito difuso e de terceira dimensão. A proteção, a recuperação a preservação são imperativos do Poder Público, visa assegurar a saúde, o bem-estar e o desenvolvimento do homem, na verdade e, em resumo, para assegurar o direito fundamental à vida.

Para Fiorillo o meio ambiente digital está relacionado diretamente ao conceito de meio ambiente cultural. O artigo 216 da Carta Maior dispõe sobre o conceito de patrimônio cultural:

\footnotetext{
Art. 216. Constituem patrimônio cultural brasileiro os bens de natureza material e imaterial, tomados individualmente ou em conjunto, portadores de referência à identidade, à ação, à memória dos diferentes grupos formadores da sociedade brasileira, nos quais se incluem:

I - as formas de expressão;

II - os modos de criar, fazer e viver;

III - as criações científicas, artísticas e tecnológicas;

IV - as obras, objetos, documentos, edificações e demais espaços destinados às manifestações artístico-culturais;

$\mathrm{V}$ - os conjuntos urbanos e sítios de valor histórico, paisagístico, artístico, arqueológico, paleontológico, ecológico e científico. (BRASIL, 2021)
}

Diante do fenômeno global, nomeado de tecnologia da informação, surge no contexto da Sociedade da Informação a "cultura digital". Esses acontecimentos refletem uma intensa interatividade comunicacional que atende e atinge todos os grupos sociais, criando uma realidade virtual no meio ambiente digital. As formas tecnológicas de interagir com a ajuda de computadores estão sujeitas às regras de comunicação, com base nos princípios prevista na Constituição Federal.

A tutela jurídica do meio ambiente digital, ou seja, a garantia do exercício do pleno direito de manifestação de pensamento e de informação realizados pelos indivíduos através dos computadores, indica a necessidade de realizar a interpretação dos artigos 220 a 224 da 
CF. Essa interpretação é a saída para suprimir a distância digital e proteger uma parte do direito ambiental mais importante do século XXI.

A transformação digital alterou diversos contextos sociais mudando as relações educacionais, as financeiras e trabalhistas. A cibercultura viabilizou os pagamentos, inscrições para concurso ou vestibular, estudar, fazer reuniões de trabalho, declarar o imposto de renda, tudo de forma digital. E o lugar onde se realiza e acontece todas essas situações é considerado uma subespécie do meio ambiente.

O meio ambiente digital pode ser entendido como sendo um local de informação, expressão de opinião onde há influências e interações através de fóruns, e-mails, bate-papos, blogs, arquivos de textos, Facebook, Instagram e Twitter. O lugar onde ocorrem as mais diversas formas de interação dos meios de comunicação existentes no século XXI. Um recinto novo, já que a internet integra sem dúvidas uma parte do meio ambiente digital, que necessita para a sua respeitável utilização a implementação de uma consciência ambiental e tecnológica para garantir uma sadia condição de vida dos seus usuários.

Inexistindo dúvidas acerca da existência de um meio ambiente digital, o próximo passo é, justamente, compreendê-lo, conforme valiosa lição de Lévy:

\footnotetext{
Que tentemos compreendê-la, pois a verdadeira questão não é ser contra ou a favor, mas sim reconhecer as mudanças qualitativas na ecologia dos signos, o ambiente inédito que resulta da extensão das novas redes de comunicação para a vida social e cultural. Apenas dessa forma seremos capazes de desenvolver estas novas tecnologias dentro de uma perspectiva humanista. (LÉVY, 1999, p. 17)
}

O ambiente digital faz parte do cotidiano de bilhões de pessoas pelo mundo, sendo que a compreensão deste espaço se torna essencial para promoção da dignidade da pessoa humana, uma vez que, reconhecendo as possibilidades de utilização deste espaço para o cometimento de crimes, o legislador poderá traçar novas estratégias para tutelar os bens jurídicos mais importantes, diante das novas formas de agressão existentes, visando, assim, preservar a dignidade da pessoa humana em todos os ambientes.

\section{LEGISLAÇÃO E INTERNET}

A educação, a cultura, a política, a economia, entre outras áreas, foram impactadas com a criação da internet. Várias foram as facilidades trazidas para o dia-dia, desde compras 
em supermercados até assinaturas de contratos milionários. Tanto o setor público quanto o privado utilizam da internet para prestarem os seus serviços. E, com isso, atingem cada vez mais pessoas através da disponibilização destes serviços.

Embora tenha trazido um grande benefício para a sociedade moderna, a sua existência facilitou a prática de crimes já existentes. Além de ter auxiliado a criação de novas práticas criminosas, gerando enormes prejuízos em todas as searas, principalmente no que tange à economia do país. Ante as novas práticas infracionais, houve alteração do ordenamento jurídico.

No Brasil, a Lei 12.965/2014, conhecida como o Marco Civil da Internet, prevê os direitos aplicáveis ao meio ambiente digital. Essa lei foi elaborada pelo Ministério da Justiça, com sugestões da sociedade civil. A maior parte de seus dispositivos reconhece os direitos fundamentais previstos na Constituição e, por tal motivo, pode-se dizer que é um instrumento mais principiológico do que regulamentador. Os princípios elencados para uso da internet, encontram-se no artigo $3^{\circ}$ do $\mathrm{MCI}$ :

\footnotetext{
Art. $3^{\circ}$ A disciplina do uso da internet no Brasil tem os seguintes princípios:

I - garantia da liberdade de expressão, comunicação e manifestação de pensamento, nos termos da Constituição Federal;

II - proteção da privacidade;

III - proteção dos dados pessoais, na forma da lei;

IV - preservação e garantia da neutralidade de rede;

$\mathrm{V}$ - preservação da estabilidade, segurança e funcionalidade da rede, por meio de medidas técnicas compatíveis com os padrões internacionais e pelo estímulo ao uso de boas práticas;

VI - responsabilização dos agentes de acordo com suas atividades, nos termos da lei; VII - preservação da natureza participativa da rede;

VIII - liberdade dos modelos de negócios promovidos na internet, desde que não conflitem com os demais princípios estabelecidos nesta Lei.

Parágrafo único. Os princípios expressos nesta Lei não excluem outros previstos no ordenamento jurídico pátrio relacionados à matéria ou nos tratados internacionais em que a República Federativa do Brasil seja parte. (BRASIL, 2014)
}

As novas tecnologias trazem um confortável modo de vida, mas junto desse conforto carregam problemas práticos que fazem com que seja necessário reflexões em relação às inovações. Como consequência também acarretam prejuízos de ordem econômica como movimentações bancárias através de fraudes eletrônicas. Nas quais o agente viola as senhas e dados cadastrais dos usuários, e de ordem emocional como publicação de fotos ou vídeos que expõe a vida pessoal e sexual sem conhecimento e autorização da vítima. 
Nesse sentido, destaca-se que “a sociedade pós-industrial passa a sofrer com novos

riscos, quais sejam, as ameaças constantes ao meio ambiente, o advento do Direito Penal econômico frente a uma política criminal arrecadatória e os direitos do consumidor." (SYDOW, 2021, p. 29). Verifica-se, portanto, que é inegável a influência das inovações tecnológicas na atual sociedade, tendo em vista que "a tecnologia ajuda a moldar uma esfera privada mais rica, porém mais frágil, cada vez mais exposta a ameaças: daí deriva a necessidade do fortalecimento contínuo de sua proteção jurídica, da ampliação das fronteiras do direito à privacidade.” (RODOTÀ, 2008, p. 95).

O avanço tecnológico, portanto, é acompanhado da criação de novos riscos inerentes a este novo ambiente, especialmente porque as possibilidades de ações aumentaram significativamente, bem como há uma maior velocidade no compartilhamento de informações e criação de novas tecnologias, o que impede, de certa forma, que o legislador consiga acompanhar todas as inovações na mesma velocidade em que estas vão surgindo.

\section{DO DIREITO À INTIMIDADE E SUA PROTEÇÃO CONSTITUCIONAL}

Todo ser humano é protegido na sua intimidade e privacidade, inicialmente através de princípios constitucionais, previstos na Constituição Federal, artigo $5^{\circ}$, inciso X: "são invioláveis a intimidade, a vida privada, a honra e a imagem das pessoas, assegurado o direito a indenização pelo dano material ou moral decorrente de sua violação". A vida privada também é protegida pelo Código Civil, através do artigo 21 que assim dispõe: “A vida privada da pessoa natural é inviolável, e o juiz, a requerimento do interessado, adotará as providências necessárias para impedir ou fazer cessar ato contrário a esta norma”. Sobre o tema, Reis e Naves afirmam que:

\footnotetext{
A intimidade é a esfera de projeção do indivíduo em sua relação interior. Já o direito à privacidade é um círculo pessoal maior, pois envolve as relações interpessoais do indivíduo. Enquanto a intimidade situa-se no compartimento mais restrito da pessoa, com situações que não se deseja compartilhar, a privacidade retrata a vida pública, familiar ou social do indivíduo, abrangendo o direito ao controle de coleta e utilização de dados pessoais. (REIS; NAVES, 2020, p. 160).
}

Com a mudança tecnológica veio também a modificação cultural. A partir da qual algumas pessoas adquiriram o hábito de fotografar todo e qualquer tipo de evento. As 
postagens nas redes sociais englobam desde o que se come, passando por uma importante data comemorativa até chegar nas publicações de fotos íntimas. Essa remodelação de comportamento, por vezes, traz prejuízos financeiros e lesões sérias com consequências psíquicas, haja vista a exposição da vida privada sem precedentes, com repercussões incomensuráveis e irreversíveis. Neste sentido, leciona Souza:

O avanço tecnológico e a popularização das redes sociais tornaram comum, nos últimos anos, o compartilhamento de conteúdo íntimo sem consentimento para número exorbitante de pessoas, devastando honras e muitas vezes dando azo a vinganças (chamadas popularmente de 'revenge porn', ou seja, pornografia de vingança) e simples humilhações impostas por pessoas de anterior relacionamento íntimo das vítimas ou mesmo terceiros que as ludibriam por tais redes. (SOUZA, 2020, p. 556)

Em alguns casos, as publicações ocorrem de forma dolosa, situações essas em que a divulgação é feita com base em motivo torpe, para expor a pessoa a uma situação vexatória, principalmente quando envolve término de relacionamento. A publicidade da vida privada e intimidade alheia através de fotografias ou vídeos de momentos íntimos, ofende a honra objetiva e subjetiva. Nesses casos, ou não houve autorização prévia, ou houve invasão do arquivo da pessoa que aparece nas imagens.

O compartilhamento de conteúdo íntimo "viralizou", gerando inúmeros constrangimentos e expondo a situações indesejáveis. Desde 2012 foi incluído ao Código Penal, pela Lei $\mathrm{n}^{\mathrm{o}} 12.737 / 2012$, preceito que pune quem invade dispositivo informático e divulga conteúdo sem autorização da pessoa exposta.

As vítimas desses atos já dispunham de instrumentos jurídicos disponíveis para a busca da compensação e do ressarcimento pelos danos sofridos. Todavia, diante do aumento significativo desse fenômeno, houve clamor social para a criminalização dessa conduta. E, como resposta jurídica ante as reinvindicações ao Estado, houve a publicação de lei incluindo como crime tal conduta. "Nessa esteira, o legislador buscou adequar a legislação aos novos desafios sociais, marcados por peculiaridades informáticas." (SOUZA, 2020, p. 556).

$\mathrm{O}$ ordenamento jurídico brasileiro nomeou essa conduta como pornografia de vingança (revenge porn) e tipificou em seu artigo 218-C do Código Penal, através da Lei

\footnotetext{
${ }^{8}$ Termo bastante comum usado pelos usuários das redes, quando há uma grande exposição de determinado conteúdo que é disseminado rapidamente em ambiente virtual atingindo indeterminado número de pessoas e tornando-se muito conhecido rapidamente, com grande repercussão.
} 
13.718/18(Brasil, 2018). Em que pese não ser um tipo de prática nova, a sua tipificação é moderna. O reflexo dela tem alcances e contornos inéditos ante a dinâmica das redes sociais, com maior capacidade de causar lesão, muita das vezes irreparáveis, por isso sua criminalização. Nesse comportamento há uma violência, não da forma tradicional, contra a intimidade sexual quando há o vazamento ou compartilhamento não consentido, mas exercida por um novo meio tecnológico através do meio ambiente digital. "O presente tipo penal, sem precedente similar na legislação brasileira, que, até agora não se havia preocupado com condutas semelhantes à aqui criminalizada, recebe agora sua proteção penal." (BITENCOURT, 2019, p. 164).

O preceito legal determina que o indivíduo que oferecer, trocar, disponibilizar, transmitir, vender ou expor à venda, distribuir, publicar ou divulgar, por qualquer meio, mídia (fotografia, vídeo, áudio etc.) que contenha cena de estupro, de vulnerável ou não, ou de sexo, nudez ou pornografia, sem o consentimento da vítima, será condenado a pena de reclusão de 1 a 5 anos. Há, também, a previsão de aumento de pena, de $1 / 3$ a 2/3, se o crime for praticado por um agente que mantém (ou manteve) relação íntima de afeto com a vítima ou agido com o fim de vingança ou humilhação.

Há uma ideia cultural e até mesmo social de que, uma vez tipificada criminalmente a conduta com penas cada vez mais recrudescidas, haverá a redução dessa prática no âmbito do meio ambiente digital. Não há comprovação de que uma vez publicada a lei houve diminuição da revenge porn, haja vista o baixo índice de denúncias e por conseguinte ausência de fontes oficiais confiáveis ${ }^{9}$. De fato, a mera criação de um tipo penal, por si só, é insuficiente para prevenir a ocorrência da conduta tipificada, uma vez que há, tão somente, uma resposta simbólica para o problema, sem, contudo, haver resultados efetivos. A divulgação e compartilhamento de dados necessita de uma conscientização e instrução das pessoas para que tenham ciência e noção dos reflexos malignos causados não só na vítima como além dela.

O Grupo de Estudos em Criminologias Contemporâneas (Gecc) - coordenado Leandro Ayres França, iniciou estudo sobre as questões que envolvia compartilhamento de conteúdo íntimo, na busca de conhecer os motivos e efeitos, bem como identificar características dos perpetradores e vítimas.

\footnotetext{
${ }^{9}$ Projeto Vazou, disponível em: https://www.projetovazou.com/.
} 
O Projeto Vazou ${ }^{10}$, finalizado em dezembro de 2018, recebeu 141 depoimentos anônimos, sendo $84 \%$ de mulheres, 16 \% homens. O objetivo era colher informações a partir das experiências das vítimas para provocar uma discussão e um incentivo ao aprendizado. A idade mais frequente à época do registro das fotos ou vídeos era de 19 anos.

Outros dados levantados foram que a maioria (81\%) informou conhecer quem vazou os arquivos. Esses eram majoritariamente do sexo masculino (84\%), com idade média de 23 anos à época da gravação. $O$ estudo também indica que o meio de compartilhamento mais comum foi a plataforma WhatsApp (70\%), seguida pelo Facebook $(26 \%)$ e que $72 \%$ das vítimas querem a punição de quem vazou o arquivo, mas em $86 \%$ dos casos sequer houve processo judicial.

A política criminal adotada foi a de tutelar penalmente a privacidade e a intimidade da vítima, em conformidade com o preceito constitucional previsto no artigo $5^{\circ}$, inciso $\mathrm{X}$, da Constituição da República. O caráter de prevenção geral e especial está previsto nesse novo dispositivo. Há, também, a nítida e a clara intenção de tornar esse preceito (primário e secundário) eficaz, eficiente e efetivo dentro do meio ambiente digital. Nesse sentido, no que se refere "à pertinência da nova figura delitiva, há de se refletir que o ramo jurídico-penal deve atualizar-se, mormente diante de conduta informática que a vulneração de direitos essenciais de personalidade da vítima, com vasto potencial de divulgação indevida." (SOUZA, 2020, p. 556).

Inobstante a legitimidade do tipo penal previsto no artigo 218-C do Código Penal, visto que serve para promover a proteção do direito fundamental da intimidade, verifica-se que a tutela penal, por si só, é insuficiente para a proteção efetiva da intimidade das vítimas da pornografia de vingança, uma vez que a opção legislativa veio desacompanhada de qualquer medida preventiva da conduta no âmbito social, mas, tão somente, houve uma resposta simbólica de um problema que é, em grande parte, cultural, especialmente nas sociedades em que o machismo possui forte influência.

É legítima a proteção do bem jurídico selecionado pela norma do artigo 218-C do Código Penal, todavia, a mera tipificação da conduta é insuficiente para proteção efetiva da intimidade das pessoas, o que reforça a ideia de adoção de medidas extrapenais voltadas para

\footnotetext{
${ }^{10}$ Tais dados foram obtidos no sítio eletrônico (site) https://www.crimlab.com/projeto-vazou, conhecido no ambiente digital como "Projeto Vazou". Por meio desse projeto, foi realizada a pesquisa, de caráter quantitativo, mencionada no desenvolvimento do presente artigo.
} 
a prevenção desse tipo de conduta, uma vez que a conscientização dos indivíduos e a compreensão do meio ambiente digital como forma para promoção da dignidade da pessoa humana podem evitar a ocorrência desse tipo de delito, de modo que o direito penal só deve atuar quando houver uma lesão efetiva ao bem jurídico tutelado, isto é, quando as formas de prevenção por meio da conscientização dos frequentadores do ambiente digital se mostrarem insuficientes para impedir a prática da conduta tipificada.

\section{CONSIDERAÇÕES FINAIS}

Durante a segunda metade do século XX, e, especialmente, durante o início do século XXI, a utilização da internet e a sua disponibilização em massa permitiu a divulgação de conteúdos com maior intensidade e de forma extremamente veloz. Outrossim, os inventos eletrônicos, como celulares e computadores, intensificaram a troca de conteúdo em massa entre várias sociedades, o que acarretou na revolução da informação.

Com essa modernização e evolução tecnológica houve uma necessidade de adequar o Direito às novas realidades implementadas no meio ambiente digital. A revolução da informação trouxe impactos no comércio, na propaganda e na vida pessoal dos indivíduos. Essas repercussões desencadearam muitos ganhos para toda a sociedade, todavia trouxe uma nova forma de ofender e denegrir as pessoas.

O meio ambiente digital surge como uma nova vertente do meio ambiente artificial, ou seja, criado pelo homem para lhe gerar maior comodidade e melhor qualidade de vida. Nesse contexto, permite o compartilhamento de informações e das atividades desenvolvidas, que tem como base a sociedade da informação.

Dentro desse ambiente virtual, que serve como meio difusor de conhecimento para facilitar a vida das pessoas, há propagação de atos ilícitos cometidos pelos indivíduos. Nesse contexto, há uma série de atos praticados dentro desse ambiente que ofende bens tutelados pelo nosso ordenamento jurídico, mas especialmente a exposição de cena de sexo, nudez ou pornografia sem o consentimento da vítima.

Diante disso, como forma de não se violar direitos no meio ambiente digital, o Direito teve que se adaptar e evoluir, garantindo inovações legislativas como o Marco Civil da Internet e a Lei Federal n. 13.718, de 25 de setembro de 2020 que tipificou o crime de Revenge Porn. 
O presente estudo objetivou evidenciar que essa evolução toda desencadeou a publicação de novas legislações. As inovações do ordenamento jurídico estão em ascensão de modo que consiga acompanhar as mudanças sociais ocorridas, garantindo uma segurança e proteção a toda sociedade.

Com esse olhar, o problema de pesquisa analisado neste estudo consistiu em verificar se a tipificação da conduta de revenge porn, por si só, é suficiente para reduzir o número de crimes cometidos no meio ambiente digital. Diante disso, o tema central do presente artigo é o meio ambiente digital e o revenge porn.

A hipótese adotada foi a de que o crime tipificado pela Lei 13.718, de 25 de setembro de 2020, que tipificou o revenge porn não é suficiente para reduzir a prática dos crimes no meio ambiente digital. Nesse sentido, são necessárias novas políticas públicas de combate aos crimes digitais.

No decorrer do estudo, demonstrou-se o avanço do ordenamento jurídico para os atos praticados dentro do meio ambiente digital. Especialmente no que tange à pornografia de vingança, com o conceito de revenge porn. Abordou a publicação da Lei 13.718/18, artigo 218-C, que criminalizou a prática dessa conduta.

Ademais, analisou-se o conceito de meio ambiente digital, bem como as evoluções legislativas que cercam o referido ambiente. Enfatizou-se, também, o Marco Civil da Internet, uma inovação legislativa à época que foi promulgado.

Por fim, explanou-se sobre o princípio da intimidade, protegido constitucionalmente, e a sua lesão quando da publicação dolosa de fotos íntimas como forma de humilhar a vítima. Discutiu-se as vertentes da internet, uma vez que ela trouxe novas possibilidades de manifestação, mas também abriu espaços para novas violações.

Entre inúmeras vantagens que surgiram com a era digital, temos fatos e condutas que demonstraram que o ordenamento jurídico-penal brasileiro precisou intervir para preservar a efetividade do direito ao meio ambiente digital de forma sadia garantindo uma digna condição de vida de seus usuários.

Todavia, a partir da análise do estudo denominado "Projeto Vazou", elaborado pelo Grupo de Estudos em Criminologias Contemporâneas (Gecc) - coordenado por Leandro Ayres França, constatou-se que a tutela penal, por si só, é insuficiente para a proteção efetiva da intimidade das vítimas da pornografia de vingança, uma vez que a opção legislativa veio 
desacompanhada de qualquer medida preventiva da conduta no âmbito social. Nesse sentido, houve uma resposta simbólica de um problema que é, em grande parte, cultural.

Diante disso, confirmando-se a hipótese levantada, a tipificação do crime de Revenge Porn não é suficiente para o combate aos crimes, especialmente de natureza sexual, cometidos no meio ambiente digital. São necessárias políticas públicas auxiliares que visem combater referidas práticas como forma de não se violar os direitos fundamentais e sociais no meio ambiente digital.

\section{REFERÊNCIAS}

BITENCOURT, Cezar Roberto. Tratado de direito penal: parte especial 4: crimes contra a dignidade sexual até crimes contra a fé pública. 13 ed. São Paulo: Saraiva Educação, 2019.

BRASIL. Código Civil. Lei n. 10.406, de 10 de janeiro de 2002. Institui o Código Civil. Disponível em: <http://www.planalto.gov.br/ccivil_03/leis/2002/110406compilada.htm. Acesso em: 21 jun. 2021.

BRASIL. Código Penal. (1940). Lei n.13.718, de 24 de setembro de 2018. Código Penal. Disponível em: <http://www.planalto.gov.br/ccivil_03/_ato2015-

2018/2018/lei/L13718.htm\#: :text=1\%C2\%BA\%20Esta\%20Lei\%20tipifica\%20os,de\%20au mento\%20de\%20pena\%20o>. Acesso em: 20 jun. 2021

BRASIL. Código Penal. Lei n. 12.737, de 30 de novembro de 2012. Código Penal. Disponível em: <http://www.planalto.gov.br/ccivil_03/_ato2011-2014/2012/lei/112737.htm >. Acesso em 20 jun. 2021.

BRASIL. Constituição (1988). Constituição da República Federativa do Brasil. Brasília: Senado Federal, Centro Gráfico, 1988.

BRASIL. Lei n 12.965, de 23 de abril de 2014. Estabelece princípios, garantias, direitos e deveres para o uso da Internet no Brasil. Disponível em: <http://www.planalto.gov.br/ccivil_03/_ato2011-2014/2014/lei/112965.htm >. Acesso em: 20 jun. 2021.

BRASIL. Supremo Tribunal Federal. Ação Direita de Inconstitucionalidade $\mathbf{n}^{0}$ 6387/DF Distrito Federal. Relator: Ministra Rosa Weber. Disponível em: <http://portal.stf.jus.br/processos/detalhe.asp?incidente=5895165>. Acesso em: 20 jun. 2021. ADIs 6387, 6388, 6389, 6390 e 6393.Disponível em: <http://portal.stf.jus.br/noticias/verNoticiaDetalhe.asp?idConteudo=462167\&ori=1>. Acesso em: 20 jun. 2021. 
BRASIL. Supremo Tribunal Federal. Ação Direita de Inconstitucionalidade $\mathbf{n}^{0}$ 6388/DF Distrito Federal. Relator: Ministra Rosa Weber. Disponível em: <http://portal.stf.jus.br/processos/detalhe.asp?incidente=5895166>. Acesso em: 20 jun. 2021 .

BRASIL. Supremo Tribunal Federal. Ação Direita de Inconstitucionalidade no 6389/DF Distrito Federal. Relator: Ministra Rosa Weber. Disponível em: < http://portal.stf.jus.br/processos/detalhe.asp?incidente=5895168>. Acesso em: 20 jun. 2021.

BRASIL. Supremo Tribunal Federal. Ação Direita de Inconstitucionalidade no 6390/DF Distrito Federal. Relator: Ministra Rosa Weber. Disponível em: < http://portal.stf.jus.br/processos/detalhe.asp?incidente=5895176>. Acesso em: 20 jun. 2021 .

BRASIL. Supremo Tribunal Federal. Ação Direita de Inconstitucionalidade $\mathbf{n}^{0}$ 6393/DF Distrito Federal. Relator: Ministra Rosa Weber. Disponível em: < http://portal.stf.jus.br/processos/detalhe.asp?incidente=5896399>. Acesso em: 20 jun. 2021 .

FIORILlO, Celso Antônio Pacheco, CONTE, Christiany Pegorari. Crimes no Meio Ambiente Digital. 2. ed. São Paulo: Saraiva, 2016.

FRADE, Camila Cristiane de Carvalho; RESENDE, Daniel Alberico; SANTOS, Henrique de Almeida. Big Data, Softwares de Inteligência Artificial (IA) e a Proteção do Meio Ambiente Marinho. In: III Encontro Virtual do CONPEDI, 2021, Florianópolis. Direito, governança e novas tecnologias I. Florianópolis: CONPEDI, 2021. v. 1. p. 134-150.

FRANÇA, Leandro Ayres. Vazamento não consentido de imagens íntimas no Brasil, 2018, Porto Alegre Brasil. Disponível em :<https://www.crimlab.com/projeto-vazou; (https://www.projetovazou.com/) >. Acesso em: 20 jun. 21.

FRANÇA, Leandro Ayres; et al. A criminalização do revenge porn: análise do art. 218-C (Código Penal). Boletim IBCCRIM, ano 26, n. 315, fev. 2019. p. 11-13. ISSN 1676-3661.

LÉVY, Pierre. Cibercultura. São Paulo: Editora 34, 1999.

REIS, Émilien Vilas Boas; NAVES, Bruno Torquato de Oliveira. O Meio Ambiente Digital e o Direito à privacidade diante do Big Data. Veredas do Direito, Belo Horizonte, v 17, n37, p.145-167, jan-abr. 2020. Disponível em:

http://revista.domhelder.edu.br/index.php/veredas/article/view/1795. Acesso em: 21 jun. 2021.

RODOTÀ, Stefano. A vida na sociedade de vigilância: a privacidade hoje. Rio de Janeiro: Renovar, 2008.

ROCHA, Anacélia Santos et al. O dom da produção acadêmica: manual de normalização e metodologia de pesquisa. Belo Horizonte: Dom Helder, 2020.

SOUZA, Luciano Anderson de. Direito penal: volume 3: parte especial: arts. 155 a 234-B do CP. São Paulo: Thomson Reuters Brasil, 2020. 
SYDOW, Spencer Toth. Curso de direito penal informático: partes geral e especial. 2 ed. Salvador: Editora JusPodivm, 2021. 